DOSSIÊ TEMÁTICO: Educação, currículo e juventudes: dilemas e desafios atuais

do1 https://doi.org/10.22481/praxisedu.v16i42.7348

\title{
O CASO DOS JOVENS NEM NEM: NOVAS TRAJETÓRIAS, NOVOS DESAFIOS
}

\author{
THE NEET YOUTH CASE: NEW TRAJECTORIES, NEW CHALLENGES
}

EL CASO DE LOS JÓVENES NI NI: NUEVAS TRAYECTORIAS, NUEVOS DESAFÍOS

\author{
Mafalda Frias \\ Universidade de Coimbra - Portugal \\ Luís Alcoforado \\ Universidade de Coimbra - Portugal \\ António Rochette Cordeiro \\ Universidade de Coimbra - Portugal
}

\begin{abstract}
Resumo: A participação dos jovens no mercado de trabalho constitui uma dimensão significativa do seu desenvolvimento pessoal e social, da construção da identidade e do desenvolvimento equilibrado e integrado das sociedades. Sendo o trabalho, ainda, o tempo social dominante, na contemporaneidade, ele é, também, a maneira mais óbvia de, permitindo o acesso a um rendimento, incrementar a autonomia e estruturar a vida quotidiana. Contudo, da evolução global dos mercados e dos sistemas económicos, derivaram consequências particularmente severas para os jovens que, experienciando percursos de carreira mais individualizados e menos previsíveis, enfrentam crescentes dificuldades na concretização dos seus projetos de vida. O progressivo aumento das taxas de desemprego, acompanhado de outras conjunturas desfavoráveis, conduziram à emergência do fenómeno NEET (not in employment, education or training), o qual assume, presentemente, grande centralidade no debate político europeu. Perante o desafio de absorver e integrar os jovens no trabalho, educação ou formação, urge conhecer, refletir e compreender as especificidades desta problemática, marcada pela heterogeneidade de contextos, características, necessidades, fatores de risco e efeitos, com vista ao delineamento de ações estratégicas concertadas que facilitem as transições entre o sistema educativo ou formativo e o mercado de trabalho. Neste artigo, caraterizamos, de forma circunstanciada o fenómeno NEET, recenseamos algumas respostas que têm vindo a ser pensadas e refletimos sobre a necessidade de despertar novos olhares e novas soluções.
\end{abstract}

Palavras chave: Jovens Nem Nem. Políticas públicas. Transição escola-trabalho.

Abstract: The participation of young people in the labor market is the main reality for the social and personal development, the construction of the identity and the balanced and incorporated development of the societies. Furthermore, work is still the dominant social time, in contemporaneity, it is also the most obvious way of allowing access to income, increasing autonomy and structuring daily life. However, from the global evolution of markets and economic systems, there have been severe 
consequences for young people who experiencing a more individualized and less predictable career paths, face growing difficulties in achieving their life projects. The increasing of unemployment rates, followed by other adverse circumstances, has led to the emergence of the NEET (not in employment, education or training) phenomenon, which is now a major focus of the European political discussion. Faced with the challenge of integrate young people into work, education or training, it is urgent to know, reflect and understand the specificities of this problem, marked by the heterogeneity of contexts, characteristics, needs, risk factors and effects, where the main goal is redesign strategic actions, concentrate efforts to facilitate transitions between the education or training system and the labor market. In this article, we define, in a detailed way the NEET phenomenon, enumerate some answers that have been thought and reflect on the need to awaken new views and solutions.

Keywords: NEET young. Public policies. School-work transitions.

Resumen: La participación de los jóvenes en el mercado laboral es una dimensión importante de su desarrollo personal y social, de la construcción de identidad y del desarrollo equilibrado e integrado de las sociedades. Dado que el trabajo sigue siendo el momento social dominante en los tiempos contemporáneos, también es la forma más obvia de permitir el acceso a los ingresos, aumentar la autonomía y estructurar la vida cotidiana. Sin embargo, a partir de la evolución global de los mercados y los sistemas económicos, han surgido consecuencias particularmente graves para los jóvenes que, experimentando carreras profesionales más individualizadas y menos predecibles, enfrentan dificultades crecientes para lograr sus proyectos de vida. El aumento progresivo de las tasas de desempleo, acompañado de otras circunstancias desfavorables, ha llevado a la aparición del fenómeno de NEET (no en el empleo, la educación o la formación), que actualmente ocupa un lugar central en el debate político europeo. Ante el desafío de absorber e integrar a los jóvenes en el trabajo, la educación o la formación, es urgente conocer, reflexionar y comprender las especificidades de este problema, marcado por la heterogeneidad de contextos, características, necesidades, factores de riesgo y efectos, para delinear acciones estratégicas que facilitan las transiciones entre el sistema de educación o formación y el mercado laboral. En este artículo, caracterizamos, de manera detallada, el fenómeno NEET, reconsideramos algunas respuestas que han estado pensando y reflexionamos sobre la necesidad de despertar nuevas soluciones.

Palabras clave: Jóvenes Ni Ni. Políticas públicas. Transiciones escuela-trabajo.

\section{Introdução}

A geração jovem afigura-se essencial ao presente e futuro das diferentes comunidades, enquanto importante fonte de competências, criatividade e dinamismo, particularmente no trabalho, entendido como "espaço e tempo mais importante de reconhecimento social" e de exercício de cidadania, nas sociedades com índices mais aceitáveis de desenvolvimento humano, integrado e sustentado (ALCOFORADO, 2008, p. 181). Neste sentido, o emprego jovem prefigura uma influente chave para o desenvolvimento económico e social, com todos e por mais tempo, mormente, num contexto de profundas alterações demográficas e consequente envelhecimento da população. Porém, tal como refere Blanch (2014, p. 356), se nos anos 60 e 
70, nos países considerados socioeconomicamente desenvolvidos, a pergunta "Estudas ou trabalhas?" era entendida como um eficaz recurso para uma primeira classificação social dos jovens, atualmente, tendo em consideração as novas dinâmicas do mercado de trabalho, a total rutura desta dicotomia é percetível, alargando os termos desta categorização para "Estudas, trabalhas ou estás desempregado?”.

A maioria das evidências demonstra que a crise económica e financeira, atravessada por diversos países, aprofundou a dificuldade dos jovens em identificar e garantir um lugar no mercado de trabalho, dada a sua alta sensibilidade às mudanças sociais e ao contexto da economia global (GAUDET, 2015). A evolução da relação entre os jovens e o emprego constitui, assim, a preocupação central de grande parte dos Estados-Membros da União Europeia (UE), a qual se justifica não só pela maior vulnerabilidade dos jovens aos efeitos da crise, em comparação com os adultos, mas também pelo facto de essas consequências apresentarem um caráter mais duradouro para o segmento mais jovem da população (O’HIGGINS, 2012).

Esta conjuntura leva-nos, incontornavelmente, a refletir sobre as trajetórias dos jovens nos dias que correm, na medida em que a transição da escola para o trabalho compreende um processo de passagem de uma condição de dependência para uma situação de autonomia e independência, enquanto fator preponderante de crescimento e maturidade pessoal, no qual está implícito um processo de estruturação social (MIRANDA, 2015, p. 64). A importância basilar da etapa da juventude para o percurso do indivíduo é evidente, pois nela operam as grandes transições para a vida adulta em termos de educação, formação e emprego. Tal facto, vem apelar à reflexão, compreensão e intervenção inadiáveis, mediante os novos contornos que caracterizam as etapas transitórias dos jovens, dado que as consequências do sucesso ou fracasso e do tempo e ordem das transições influenciam, substancialmente, as oportunidades de vida de um indivíduo (ELDER; KIRKPATRICK; CROSNOE, 2004).

$\mathrm{Na}$ verdade, os jovens do séc. XXI têm vindo a enfrentar profundas alterações e incertezas no seu processo de transição para a vida adulta, decorrentes da combinação de um conjunto de fatores socioeconómicos e políticos. A complexidade e a competitividade, características do atual mercado de trabalho, deram origem a percursos educativos mais extensos e a "inserções laborais mais tardias e instáveis", a par do adiamento de um conjunto de tarefas típicas do início da idade adulta (MENDONÇA; ANDRADE; FONTAINE, 2009, p. 147). A este respeito, Arnett (2000) introduz o conceito de "adultez emergente", referindo-se a um período mais alargado da experiência educativa e a um atraso no acesso ao trabalho 
remunerado. Nesta etapa, os jovens defrontam-se com a contradição de já não serem adolescentes, mas, ao mesmo tempo, não usufruírem do estatuto e atributos habituais da idade adulta. O período de vida situado entre a adolescência e a idade adulta encontra-se imbuído de complexidade, não só porque se tem alargado, mas também porque se diversifica, tornando-se "cada vez menos unidimensional e unívoco" (GAUDET, 2015, p. 33).

Portanto, ainda que a integração na sociedade tenha sido, tradicionalmente, imaginada como uma sequência de fases da escola para o trabalho, é agora reconhecido que essas transições lineares estão a ser, cada vez mais, substituídas por longas trajetórias do sistema de ensino para o mercado de trabalho, totalmente diversificadas e individualizadas, tendo em linha de conta os percursos e características de cada indivíduo (EUROFOUND, 2012). De igual forma, sabe-se que, à medida que os contextos sociais mudam, cada grupo enfrenta distintas barreiras e oportunidades que moldam os seus futuros (BYNNER; PARSONS, 2002). Com efeito, a não integração nos principais subsistemas sociais - emprego, educação e formação constitui um forte indicador de falhas graves relativamente a esta transição, razão pela qual os jovens NEET (not in employment, education or training) ${ }^{1}$ têm atraído, nos últimos anos, grande centralidade no debate político europeu (EUROFOUND, 2012). A dificuldade em assegurar transições satisfatórias, alicerçadas em trabalho digno, abrange outros problemas, igualmente reveladores do fracasso destes novos processos, designadamente, a geração freeter, a geração canguru e a geração boomerang ${ }^{2}$ (REIKO, 2006; STONE III, 2014).

Indubitavelmente, o desvio do modelo básico de transições da escola para o trabalho, pautado por percursos cada vez mais diversificados, nos quais se insere a questão do abandono escolar precoce e a consequente inatividade, é verdadeiramente inquietante. A relação entre o fenómeno NEET e os baixos níveis de qualificação escolar e profissional dos jovens tem vindo a desencadear crescentes e complexos desafios aos Estados-Membros da União Europeia, obrigando ao delineamento de estratégias concertadas que contribuam, por um lado, para a superação de um quadro marcado pelo défice de criação de emprego e pelo desemprego de longa duração e, por outro lado, para o combate ao expressivo desalinhamento entre as exigências de um mercado de trabalho cada vez mais competitivo e as competências e

\footnotetext{
${ }^{1}$ Em conformidade com a designação em uso na literatura científica internacional, numa lógica de unificação de análise, neste trabalho adotaremos o termo inglês NEET.

${ }^{2}$ Geração freeter: jovens que vagueiam por trabalhos precários e mal remunerados; geração canguru: jovens que vão adiando a saída de casa dos pais até idades tardias; geração boomerang: jovens que apesar das tentativas de autonomização, regressam à casa dos pais, face à incapacidade de rendimentos adequados.
} 
qualificações dos jovens, bem como as suas expetativas e representações da escola e do mundo laboral.

Reconhecendo o caráter multidimensional da problemática dos jovens que não estudam nem trabalham, e a complexidade de todos os aspetos a ela associados, através da literatura disponível e dos relatórios oficiais mais recentes, neste trabalho, apresentaremos a problemática NEET, enquadrando-a em termos concetuais e teóricos. Neste seguimento, propomo-nos caracterizar e compreender os fatores de risco e os efeitos psicossociais inerentes à situação NEET, assim como identificar e descrever algumas das respostas políticas desenvolvidas no âmbito da qualificação e promoção do emprego para estes jovens, finalizando com uma análise crítica às principais dimensões deste fenómeno tão complexo.

\section{Origem e evolução do acrónimo NEET}

O acrónimo NEET surgiu, pela primeira vez, a nível político, no Reino Unido, em finais dos anos 90, numa publicação governamental - Bridging the Gap Report (SEU, 1999), visando a identificação de novos critérios de avaliação das vulnerabilidades dos jovens com idades compreendidas entre os 16 e os 18 anos, que não se encontravam inseridos em qualquer sistema de emprego, educação ou formação, nem eram contemplados nas estatísticas oficiais do desemprego. Posteriormente, em consequência da recessão económica e das estatísticas avançadas por organizações supranacionais, o fenómeno NEET desencadeou, no seio da União Europeia, um progressivo interesse e preocupação, face à necessidade de um indicador adequado à referenciação dos jovens inativos desvinculados do trabalho, educação e formação. A inexistência de um indicador NEET, internacionalmente reconhecido, despoletou uma multiplicidade de definições, levando a que Organizações Internacionais ${ }^{3}$ implementassem a sua própria definição de NEET, de forma a estabelecer um padrão que viesse facilitar qualquer abordagem à problemática. Então, em 2010, o Comité do Emprego da União Europeia delimitou, na sua definição NEET, jovens entre os 15 e os 24 anos de idade, desempregados ou inativos, tal como aqueles que se encontravam afastados do sistema educativo/formativo, passando esta definição a ser usada no conjunto de indicadores do Eurostat (EUROFOUND, 2012). Importa clarificar que, apesar desta definição mais generalista e para efeitos estatísticos, as faixas etárias poderão assumir uma certa variabilidade, sendo apresentadas, por vezes,

\footnotetext{
3 Comissão Europeia (CE) e Organização para a Cooperação e Desenvolvimento Económico (OCDE)
} (EUROFOUND, 2016; OCDE, 2018). 
informações relativas a grupos etários entre os 15 e os 24, 29 ou 34 anos (EUROFOUND, $2012)^{4}$.

A sensação de que os indicadores estabelecidos no mercado de trabalho não captavam eficazmente as tendências dos mercados contemporâneos, revelando-se insuficientes para a caracterização dos jovens no domínio laboral e, consequentemente, pouco eficazes no que concerne ao direcionamento de políticas promotoras da sua entrada no trabalho, desencadeou a introdução do termo NEET como indicador estatístico do desemprego e da situação social dos jovens, no quadro da Estratégia de Crescimento Europa 2020, paralelamente à taxa de desemprego juvenil e à taxa de desemprego. A taxa NEET representa, assim, a relação entre a população jovem de um determinado grupo etário que não estuda nem trabalha e a população total de jovens do mesmo grupo etário (EUROFOUND, 2012).

Em comparação com a primeira definição britânica, as aceções que se seguiram ampliaram o horizonte de análise, fazendo com que o indicador europeu captasse um grupo mais heterogéneo do que o indicador inglês (HOLTE, 2017). O objetivo deixa de estar exclusivamente centrado no período imediatamente após a escolaridade obrigatória e no direito e dever à educação/formação, passando a estender-se a toda a juventude e ao processo de transição para o trabalho que, em tempos de crise, tende a prolongar-se no tempo (BATINI; CORALLINO; TOTI; BARTOLUCCI, 2016). A delimitação de faixas etárias mais amplas permitiu explorar um conjunto mais alargado de tendências, nomeadamente, algumas conjunturas familiares (casamento, filhos), conclusão de percursos educativos/formativos e experiências de trabalho. Enquanto a pesquisa britânica obteve os dados através de estudos de coorte e entrevistas com jovens NEET, a abordagem europeia privilegiou dados de estudos padronizados, como é exemplo a pesquisa sobre a força de trabalho, facilitando a comparação entre países (HOLTE, 2017).

A introdução de novos conceitos, como NEET, Freeter ${ }^{5}$ e Hikikomori ${ }^{6}$ poderá constituir um bom contributo para a captação das condições precárias dos jovens na atualidade, contudo,

\footnotetext{
${ }^{4}$ Embora o principal indicador NEET (de acordo com o Eurostat) se direcione para a faixa etária dos 15-24 anos, este indicador é desagregado por sexo e disponibilizado para diferentes faixas etárias, de modo a possibilitar múltiplas análises.

${ }^{5}$ Neologismo introduzido no Japão, no final da década de 80, composto pela palavra inglesa "Free" e pela palavra alemã "Arbeiter" (trabalhador), correspondendo a jovens com idades entre os 15-34 anos que não encontram emprego a tempo integral, permanecendo em trabalhos precários, temporários ou a tempo parcial após deixarem o sistema de ensino (Reiko, 2006).

${ }^{6}$ Introduzido no Japão, pertence a uma subcategoria da conjuntura NEET, composta por jovens que não só evitam um envolvimento profissional, como também se desviam da participação social, conduzindo ao extremo isolamento (Batini et al., 2016).
} 
para que tal suceda é fundamental criar condições que garantam, por parte das políticas governamentais, um efetivo reconhecimento destas situações de maior desfavorecimento, afastando, assim, perceções equivocadas sobre as causas do problema. Só identificando com maior exatidão a situação destes jovens, através da estabilização de novas categorias e métodos de pesquisa mais rigorosos, poder-se-á disponibilizar informação mais ajustada aos decisores políticos, permitindo uma concentração direcionada das intervenções naqueles que mais precisam, adequando-as igualmente às atuais caraterísticas do mundo do trabalho (INUI, 2005) e criando condições para as transformar progressivamente, no sentido das necessidades e projetos desses jovens. Importa, ainda, salientar que o termo NEET não surgiu com o intuito de descrever a identidade de indivíduos ou grupos, mas sim, com o propósito de obter uma classificação oficial dos jovens, no que ao mercado de trabalho e sistema educativo diz respeito (PUBLIC HEALTH ENGLAND, 2014).

\section{NEET, um fenómeno heterogéneo: características, fatores de risco e efeitos psicossociais}

Contrariando o cenário de uma conjuntura bem definida e homogénea, os dados existentes revelam que o fenómeno NEET engloba uma grande diversidade de trajetórias, acompanhadas por distintas características económicas, sociais e pessoais, assim como fatores de risco e efeitos diferenciados (EUROFOUND, 2016). Além de heterogéneo, este grupo assume uma condição dinâmica, dado que, teoricamente, os jovens podem sair e voltar a imergir nesta complexa posição. Não obstante, a análise das transições entre a escola e o mundo laboral mostra que a situação dos jovens NEET não vislumbra um estado temporário, podendo, pelo contrário, persistir por longos períodos de tempo (FLISI; GOGLIO; MERONI; VERATOSCANO, 2015; CARCILLO; FERNANDEZ; KONIGS; MINEA, 2015).

Esta ampla categoria abrange não só jovens desencorajados, que abandonaram precocemente a escola, mas também jovens altamente qualificados que, ainda assim, não conseguem alcançar um lugar no mundo laboral. Da mesma forma, deparamo-nos com jovens que se afastam do mercado de trabalho de forma voluntária e jovens que, involuntariamente, são integrados nesta categoria, por várias razões. Neste contexto, considerando a extensão da problemática NEET, e de modo a alcançar um melhor entendimento dos traços deste grupo, encontram-se identificados cinco subgrupos principais ${ }^{7}$ : os desempregados convencionais -

\footnotetext{
7 Grupos identificados pela European Foundation for the Improvement of Living and Working Conditions (Eurofound, 2012).
} 
desempregados de longa e curta duração; os não disponíveis - devido a doença/incapacidade, responsabilidades familiares, entre outros; os desencorajados - jovens inativos que não procuram emprego, educação ou formação; os que procuram uma oportunidade - jovens que, apesar de procurarem ativamente trabalho/formação, aguardam uma oportunidade consentânea com as suas competências e qualificações; e, por fim, os voluntários - jovens que optaram por estilos de vida alternativos (EUROFOUND, 2012). Cada um destes subgrupos apresenta características muito particulares do ponto de vista sociodemográfico, conduzindo a determinados fatores explicativos dos padrões de vulnerabilidade, daí que sejam elencadas duas grandes subcategorias: os NEET vulneráveis, em risco de marginalização e, muitas vezes, desprovidos de capital social, cultural e humano, e os NEET não vulneráveis, que correm pouco risco de marginalização (EUROFOUND, 2012).

Perante um grupo tão heterogéneo e tendo em consideração que tamanha pluralidade poderá interferir na leitura e reconhecimento das barreiras existentes, desviando o foco das políticas, torna-se fundamental compreender, cautelosamente, os fatores que levaram a que diferentes jovens se tornassem NEET, no sentido de impulsionar um conjunto de intervenções adequadas à multiplicidade de circunstâncias (INUI, 2005). Ainda que caracterizados de maneira diversa, os jovens NEET tendem a partilhar um conjunto de vulnerabilidades associadas à pertença a classes socioeconómicas mais baixas que, por sua vez, ao contribuirem, expressivamente, para o aumento da probabilidade de um jovem se tornar NEET, se constituem como preditor significativo de limitação de oportunidades futuras, nas diferentes esferas dos seus percursos de vida.

Parece existir algum consenso sobre a consideração do nível de qualificação dos jovens, como principal fator preditivo de risco, uma vez que os jovens com baixos níveis de qualificação têm uma probabilidade três vezes maior de enveredar por um quadro NEET, comparativamente aos jovens que concluem estudos de nível superior (EUROFOUND, 2012). E se, por um lado, os jovens com baixos níveis de qualificação se inserem, maioritariamente, na categoria dos que não procuram emprego (inatividade), por outro lado, os jovens com formação superior correspondem àqueles que mais procuram emprego (NEET desempregados) (YUJI, 2005). Importa, neste contexto, enunciar as diferenças existentes entre estas duas dimensões de análise: a inatividade e o desemprego. Enquanto os jovens NEET desempregados se mantêm num processo de procura ativa de emprego, através dos seus próprios meios ou por intermédio de entidades que prestam apoio a este nível, os jovens NEET inativos não procuram trabalho por razões variadas (e.g. indisponibilidade pessoal face a responsabilidades familiares 
ou doença, desencorajamento, etc), nem estão inscritos nos serviços públicos de emprego, causando graves dificuldades em termos da sua sinalização e posterior intervenção (EUROFOUND, 2012).

Flisi et al (2015, p. 24) confirmam o valor do investimento na educação, na medida em que, "em todos os países da UE28, a proporção de NEET é maior entre indivíduos de baixa escolaridade e, para a maioria dos países, esta proporção diminui com o aumento do nível de qualificação". Ainda que o valor da educação não possa circunscrever-se a uma relação com o emprego, sendo fundamental garantir uma formação mais holística, que tenha em consideração a dimensão pessoal e cultural, mas também social e cívica, não deixa de ser preocupante registar esta relação entre os níveis de escolaridade e as probabilidades de uma socialização profissional com menos direitos e oportunidades. Por outro lado, ainda que os jovens com baixa escolaridade se vejam numa posição nitidamente mais desfavorecida, um nível de educação superior não representa um passaporte para o trabalho e muito menos para situações que configurem o desenho de carreiras suportadas em emprego digno. Efetivamente, jovens NEET que detêm uma qualificação até ao nível $4^{8}$ estão sobrerrepresentados, ainda que, dando conta de um dos efeitos da mais recente crise económico-financeira, é possível detetar um aumento de jovens NEET com níveis de qualificação entre 5 e 8 (BĂLAN, 2017). De forma consentânea, o trabalho de Alcoforado, Frias, Cordeiro, Fonseca \& Oliveira (2018) aponta para uma sobrerrepresentação de jovens adultos que abandonaram precocemente o sistema educativo e, simultaneamente, para um número crescente e significativo de jovens com nível de ensino superior.

Os problemas de saúde e relativos a diferentes incapacidades concorrem, igualmente, para o aumento da probabilidade de um jovem seguir uma trajetória NEET, quando comparado com outros jovens, sendo vários os estudos a comprovar a associação entre as necessidades educativas especiais e a situação NEET (COLES, B., HUTTON, S., BRADSHAW, J., CRAIG, G., GODFREY, C., \& JOHNSON, J., 2002; SEU, 1999). Em termos de saúde mental, constatase que a condição NEET pode agravar os sintomas depressivos, levando a um maior isolamento social e a uma menor intervenção cívica (O’DEA, B.; GLOZIER, N.; PURCELL, R.; MCGORRY, P.; SCOTT, J.; FEILDS, K.; HERMENS, D.; BUCHANAN, J., SCOTT, E.,

\footnotetext{
${ }^{8}$ Quadro Europeu de Qualificações (QEQ): nível 1 ( $2^{\circ}$ ciclo do ensino básico); nível 2 (3 ciclo do ensino básico obtido no ensino regular ou por percursos de dupla certificação); nível 3 (ensino secundário vocacionado para o prosseguimento de estudos de nível superior); nível 4 (ensino secundário obtido por percursos de dupla certificação ou ensino secundário vocacionado para o prosseguimento de estudos de nível superior acrescido de estágio profissional de, no mínimo, 6 meses); nível 5 (qualificação de nível pós-secundário não superior com créditos para o prosseguimento de estudos de nível superior); nível 6 (licenciatura); nível 7 (mestrado); nível 8 (doutoramento).
} 
YUNG, A.; KILLACKY, E.; GUASTELLA, A.; HICKIE, I., 2014). Os jovens NEET são, também, mais propensos ao consumo de substâncias psicoativas e a seguir os caminhos do crime e da violência (HENDERSON; HAWKE; CHAIM, 2017). A imigração reflete, similarmente, outro dos fatores de risco inerentes à conjuntura NEET, estando demonstrado que os imigrantes ou descendentes de imigrantes apresentam maior probabilidade (em 70\%) de se tornarem NEET do que um nacional (EUROFOUND, 2012).

O papel dos fatores sociodemográficos, tal como o impacto da precariedade laboral nos contextos familiares, tem sido amplamente citado na literatura, face à acumulação de desvantagens económicas e consequente redução das oportunidades de realização académica e profissional dos jovens. Claramente, ter pais desempregados aumenta a probabilidade de um jovem seguir uma trajetória NEET, em comparação com aqueles com pelo menos um dos pais empregado (ZUCCOTTI; O'REILLY, 2018). Da mesma forma, Schoon (2014) vem demonstrar a significativa relação entre o desemprego dos pais e níveis mais baixos de realização escolar entre os descendentes, além de uma experiência prolongada de NEET entre os 16 e os 20 anos de idade. Um contexto familiar com fracos recursos socioeconómicos contribui, de forma expressiva, para a experiência NEET (EUROFOUND, 2012; BYNNER; PARSONS, 2002; ARCEO; CAMPOS, 2011). De salientar, ainda, que a proveniência de famílias economicamente desfavorecidas, aumenta a predisposição dos indivíduos a condições de trabalho precárias e, posteriormente, ao abandono dos seus postos de trabalho (YUJI, 2005). Se as características da base económica da família afetam a probabilidade de pertencer à categoria NEET, tal condição deverá ser entendida como um caminho de transmissão intergeracional da pobreza, na medida em que a pobreza familiar, vivenciada durante o período da adolescência, representa um elemento potenciador de uma trajetória NEET, durante o início da idade adulta (NOH; JOO LEE, 2017).

Para além da influência dos episódios de desemprego parental, o nível de escolaridade dos pais assume um papel preponderante na predição da trajetória NEET, pois os jovens cujos progenitores apresentam baixos níveis de qualificação são 1,5 vezes mais propensos a tornaremse NEET do que os jovens cujos pais concluíram o ensino secundário (EUROFOUND, 2012). Em particular, quanto maior o nível de qualificação da mãe, menor será a probabilidade de o seu filho ser NEET (ALFIERI; SIRONI; MARTA; ROSINA; MARZANA, 2015). Evidenciase, ainda, a consequente incapacidade de os ascendentes apoiarem e aconselharem os seus filhos relativamente ao sistema educacional (RENNISON; MAGUIRE; MIDDLETON; ASHWORTH, 2005). Notoriamente, as atitudes e o apoio dos pais desempenham um papel 
fundamental na tomada de decisões dos jovens, no que concerne às suas carreiras, uma vez que potenciam o aumento da probabilidade de o jovem prosseguir os seus estudos. Pelo contrário, o capital do lar assente na falta de interesse dos pais na educação dos filhos são fortes preditores da experiência NEET (BYNNER; PARSONS, 2002).

De igual forma, ressalta a importância do contexto, já que as suas peculiaridades influenciam, significativamente, o percurso de vida dos jovens nos mais variados domínios. A este respeito, Schoon (2014) revela que viver em zonas geográficas altamente desfavorecidas e em casas arrendadas constituem fatores de risco independentes para a situação NEET. O trabalho de Rennison et al (2005) sugere que os jovens do grupo NEET tinham duas vezes mais probabilidades de viver em bairros sociais, em comparação com outros grupos de jovens. Igualmente notórias são as divergências entre zonas rurais e urbanas, sendo a taxa NEET menor no setor urbano, comparativamente à média nacional, o que pressupõe a existência de um maior número de NEET no setor rural (ARCEO; CAMPOS, 2011). Tendo em linha de conta todas as características e fatores de risco apresentados, verifica-se que a probabilidade de um indivíduo se tornar NEET não é distribuída de forma aleatória ou idêntica, pois aqueles que já enfrentavam adversidades, como a pobreza, são mais propensos a seguir, em algum momento, percursos determinados pelo afastamento dos principais subsistemas sociais (PUBLIC HEALTH ENGLAND, 2014).

O preocupante retrato do fenómeno dos jovens que não estudam nem trabalham, encaminha-nos, também, a refletir sobre os efeitos produzidos na sua vida pessoal e profissional, os quais apresentam inequívoca interligação com a problemática do abandono escolar precoce 9 . Mesmo perante a "geração mais formada a nível académico de sempre" (RODRIGUES, 2016, p. 67), os governos enfrentam, ainda, o grave problema de uma participação elevada de jovens que abandonaram o sistema de ensino sem concluir a escolaridade obrigatória. Entre os principais determinantes do abandono escolar precoce encontra-se um conjunto de condições associadas a diferentes dimensões: a nível familiar, destaca-se o baixo estatuto socioeconómico, o contexto de imigração e o género ${ }^{10}$; ao nível da escola, ressalta a retenção (considerada contraproducente), a segregação socioeconómica e os cuidados e experiências proporcionadas na primeira infância, bem como a transição para o

\footnotetext{
${ }^{9} \mathrm{O}$ abandono escolar precoce refere-se, de um modo geral, a jovens com idades compreendidas entre os 18 e os 24 anos, que não frequentam o sistema educativo/formativo e cujo nível de escolaridade não ultrapassa o ensino básico (EUROPEAN COMMISSION; EACEA; EURYDICE; CEDEFOP, 2014).

${ }^{10}$ Em todos os países europeus (excepto Bulgária e Turquia), os rapazes são mais propensos a abandonar a escola, comparativamente às raparigas (FLISI et al, 2015)
} 
ensino secundário; por fim, relativamente à dimensão do trabalho, é de referir a interferência de oportunidades de emprego (muitas vezes sazonais e de baixa qualificação), a nível local, na decisão do aluno de abandonar a escola prematuramente (FLISI et al, 2015).

Da saída antecipada do sistema de ensino resulta um quadro altamente desafiador, não apenas para os jovens, mas também para a sociedade, colocando graves dificuldades do ponto de vista da coesão social. Assim, o abandono escolar precoce levará a oportunidades mais reduzidas no mercado de trabalho e a uma maior probabilidade de desemprego, inatividade, pobreza, exclusão social, problemas de saúde e participação limitada em atividades de cariz político, social e cultural, sendo que o impacto destes efeitos negativos na geração seguinte pode perpetuar a ocorrência de abandono escolar precoce (EUROPEAN COMMISSION; EACEA; EURYDICE; CEDEFOP, 2014).

Uma melhor educação poderá facilitar a obtenção de resultados mais positivos em termos de emprego, nível de salários, melhor saúde, menor criminalidade, maior coesão social, menores custos públicos e maior produtividade (OOMEN; PLANT, 2014). Todavia, as dinâmicas educativas não devem priorizar uma função estanque de preparação para o trabalho em detrimento de outras dimensões da vida, individual e coletiva. Se, porventura, a escola se transformasse numa mera formação destinada às necessidades das empresas, gradualmente submeter-se-ia à lei do mercado, assumindo um "investimento mais financeiro do que cultural" (SUE, 1999, p. 115). Neste sentido, torna-se essencial garantir uma visão muito mais aberta, assente numa escola que se concebe, também, como um espaço e tempo privilegiados de educação holística e integrada, problematizadoras e transformadoras da vida.

A não participação em emprego, educação e formação, muitas vezes decorrente de uma circunstância de abandono escolar precoce, vem acentuar e ampliar alarmantes consequências de curto e longo prazo nos percursos dos jovens, incluindo desemprego de longa duração, frágil saúde física e mental, abuso de drogas e álcool, parentalidade em idade precoce e atividades criminosas (COLES et al, 2002). A experiência NEET simplesmente agrava uma história de insucesso escolar, reduzindo as perspetivas de emprego ou a aquisição de capital humano através de educação/formação (PUBLIC HEALTH ENGLAND, 2014). Inevitavelmente, tal condição acarreta consequências sociais e económicas específicas, destacando-se a falta de confiança e a descrença nas instituições, a menor participação e interesse a nível social e político, assim como a diminuição da produtividade e retorno económico (EUROFOUND, 2012). Importante será dizer que o fenómeno NEET encerra duas grandes preocupações, designadamente, a dificuldade acrescida por parte dos jovens em tornarem-se trabalhadores 
estáveis, com direitos e perspetivas de emprego a longo prazo e a dependência permanente (dos pais) em que muitos destes jovens vivem (REIKO, 2006).

\section{Limitações e controvérsias em torno do conceito NEET}

A natureza heterogénea do fenómeno NEET, face à multiplicidade de características, fatores de risco e efeitos psicossociais, conduz a um aspeto de crucial importância que jamais poderá ser menosprezado: a relação entre os fatores individuais e estruturais envolvidos em todo este processo. Efetivamente, a precariedade que caracteriza o mercado de trabalho contrasta com uma sociedade do conhecimento altamente qualificada, promovendo a participação na educação e expectativas sociais mais elevadas, mas todas imersas num ambiente crónico de desemprego, subemprego e desigualdade juvenis (SIMMONS; SMYTH, 2016). Nesta linha de ideias, a experiência NEET não deverá ser explicada, somente, em termos dos valores e atitudes dos indivíduos e das escolhas (muitas vezes condicionadas) que eles fazem, nem sequer ser assumido como um problema assente na frágil empregabilidade da população jovem. Ao invés disso, deve ser entendida como o resultado de um descompasso sistémico entre o sistema económico e o sistema educativo que caracteriza o desenvolvimento acelerado do capitalismo nas sociedades contemporâneas (SERGI; CEFALO; KAZEPOV, 2018; THOMPSON, 2011). Indubitavelmente, a reflexão sobre a utilidade e eficácia desta nova categoria assume particular interesse. Com efeito, será este novo conceito capaz de retratar as vulnerabilidades dos jovens no mercado de trabalho e compreender devidamente a sua complexidade? Tratar-se-á de uma categoria eficaz para delinear respostas políticas adequadas?

De acordo com Serracant (2014), a expansão e consolidação deste novo indicador fezse acompanhar por graves condicionantes que, não tendo, ainda, sido ultrapassadas, muito por força da ausência de linearidade nas trajetórias dos jovens e da pluralidade de fatores e razões que podem concorrer para a situação NEET, não permitem encaixar os jovens numa simples dicotomia de NEET e não NEET (ROBERTS, 2011). Percecionada, por muitos, como uma definição estreita e redutora, ao direcionar todas as atenções para os jovens NEET, os decisores políticos acabam por descurar a posição dos jovens que abandonam a escola e integram de imediato o mercado de trabalho, porém, em empregos efémeros, marcados pela insegurança e precariedade (BENTLEY; GURUMURTHY, 1999). A utilidade do conceito NEET, enquanto categoria, acaba, portanto, por ficar comprometida pelo facto de combinar duas circunstâncias opostas, designadamente, a de jovens desfavorecidos, com escassos recursos, e a de jovens mais 
privilegiados, com capacidade de exercer escolhas ao longo das suas transições (FURLONG, 2006). Dito de outro modo, para que esta categoria possa revestir-se de maior utilidade e eficácia, em termos de respostas políticas, é essencial que a classificação usada capture a desvantagem, em vez do movimento voluntário inerente ao modo de vida dos jovens mais favorecidos.

Entre as principais limitações ${ }^{11}$ deste novo conceito destacam-se: a heterogeneidade, visto que a abrangência etária do indicador amplia o número potencial de jovens e situações (como é exemplo a situação de jovens mais favorecidos que, voluntariamente, se inserem nesta categoria), enfraquecendo a sua ligação com a exclusão social; a individualização, já que a sua abordagem tende a focar os jovens e as suas limitações, deixando para segundo plano os fatores estruturais associados às desigualdades sociais e às políticas ineficazes; a criação de políticas inadequadas, como consequência de uma abordagem individualizada; o esquecimento de outros grupos e situações de risco (desemprego de longa duração; precariedade laboral), face à centralidade em torno da condição NEET; e por fim, o facto de se tratar de um fenómeno exclusivamente centrado nos jovens, perante uma realidade que ocorre em todas as faixas etárias, envolvendo jovens e adultos (SERRACANT, 2014).

Importa, igualmente, analisar a conotação negativa que o rótulo NEET tem vindo a adquirir, desencadeada, em grande parte, pela abordagem individualizada desta nova categoria. Esta abordagem poderá estar a contribuir para a marginalização e estigmatização dos jovens NEET (THOMPSON, 2011) ao vincular-se a determinados estereótipos, como a ociosidade e o conformismo, fazendo com que o fenómeno NEET seja assumido como um exemplo daquilo que pode ser caracterizado como a culpabilização das vítimas (COLE, 2008). Atendendo a todas as considerações tecidas, urge desenvolver uma abordagem que seja mais sensível às transformações e desigualdades sociais, sedimentando novas formas de capturar a vulnerabilidade dos jovens, além da categoria NEET, já que esta, tal como a conhecemos, não permite fornecer uma base sólida voltada para respostas políticas adequadas e eficazes (FURLONG, 2006).

\footnotetext{
${ }^{11}$ Face às limitações apresentadas, e de modo a reduzir a heterogeneidade das situações inerentes ao termo NEET, é proposto um novo indicador - NEET restrito -, que se assume como um complemento e uma alternativa ao indicador NEET da OCDE/Eurostat. Esta nova possibilidade refere-se à população que não trabalha, não estuda, nem deseja fazê-lo, concentrando-se nos indivíduos incluídos em cada uma das seguintes condições: não estão a estudar; não estão a trabalhar; não estão à procura de emprego; e não estão doentes ou incapacitados (SERRACANT, 2014).
} 


\section{Um olhar pelas principais tendências: dados estatísticos}

Em 2015, a União Europeia totalizava quase 90 milhões de pessoas com idades compreendidas entre os 15-29 anos (17\% da sua população), encontrando-se estes jovens em situações diversificadas, cujos padrões de qualificação e emprego variavam, substancialmente, entre os Estados-Membros. Na faixa etária em análise, o número total de jovens NEET era pouco menos de 14 milhões, correspondendo a uma taxa NEET de 14,8\% (EUROFOUND, 2016). O período entre os 15-29 anos de idade, deveras extenso, é marcado por inúmeras transformações características das etapas da adolescência e da idade adulta jovem, daí que a sua divisão por grupos etários restritos possibilite uma análise mais eficiente e real das distintas situações em que os jovens se encontram. Presumivelmente, neste intervalo, uma mudança clara e expressiva ocorre da esfera educativa para a esfera do emprego. Se, por um lado, na maioria dos países, a faixa etária dos 15-19 anos corresponde ao final do ensino secundário e, naturalmente, à transição para o mercado de emprego ou para o ensino superior, por outro lado, os períodos entre 20-24 anos e 25-29 anos caracteriza-se por uma maior autonomia financeira, já que, supostamente, os jovens deixam o sistema educativo e ingressam no mercado de trabalho.

Na média dos países da OCDE, o recente relatório Education at a Glance 2018 (OCDE, 2018) revela que cerca de $40 \%$ dos jovens com idades entre os 20-24 anos já não se encontram no sistema educativo e estão empregados, sendo que esta percentagem aumenta para mais de $65 \%$ entre os jovens de 25-29 anos. De facto, nem todos os jovens que deixam o sistema de ensino encontram trabalho e, quando tal acontece, muitos são os que se sujeitam a condições de trabalho extremamente precárias, motivadas pela falta de experiência profissional. De acordo com dados de 2017 e, focando o período mais alargado, situado entre os 15-29 anos, nos países da OCDE, em média, 13,4\% dos jovens não estudam nem trabalham. Com base na divisão por grupos etários, verifica-se que a taxa NEET sofre um aumento considerável à medida que a idade vai avançado: enquanto a faixa etária dos 15-19 anos apresenta uma taxa NEET de 5,9\%, no período entre os 20-24 anos sobe para os $15,6 \%$, atingindo $17,7 \%$ na faixa etária entre os 25-29 anos (OCDE, 2018).

Numa análise às tendências de género, na média dos países da OCDE, ressalta uma diferença mínima de 2 pontos percentuais entre o sexo masculino e feminino, ainda que se registe uma variação significativa entre países. As disparidades ganham maior expressão no que aos NEET inativos diz respeito, verificando-se, em quase todos os países da OCDE, uma 
clara prevalência de jovens do sexo feminino. Em média, em 2017, mais de 65\% das mulheres NEET são inativas, enquanto a parcela não atinge 50\% entre os homens NEET (OCDE, 2018). Estes dados são consensuais com um resultado padrão verificado na literatura e relatórios internacionais, que indicam uma taxa NEET tipicamente maior para o sexo feminino (OCDE, 2014; SUSANLI, 2016; BĂLAN, 2017). Em 2016, quase um quarto (22,7\%) das mulheres com idades compreendidas entre os 20-34 anos, na UE28, eram NEET, em comparação com apenas 14\% dos homens. De salientar, que as mulheres NEET são mais propensas à inatividade, enquanto os homens tendem a estar desempregados, uma propensão que se justifica pela dedicação da mulher às tarefas domésticas e outras responsabilidades familiares, pois mais de metade vive com o seu companheiro, o que contrasta com a realidade dos homens, já que a maior parte reside com os seus pais (AGUILA; MEJÍA; PÉREZ; RIVERA; RAMÍREZ, 2013). De acordo com a OIT, mais de três em cada quatro $(76,9 \%)$ dos jovens NEET são mulheres, o que se relaciona fortemente com as normas sociais que impulsionam os resultados desiguais do mercado de trabalho entre homens e mulheres (INTERNATIONAL LABOUR ORGANIZATION, 2017).

Analisando o cenário português, de acordo com dados da OCDE (2014), Portugal surgia como um dos países mais afetados pelos efeitos da recente crise económica e financeira, particularmente no que se refere ao setor da educação e da integração dos jovens no mercado de trabalho, apresentando a décima taxa NEET mais elevada entre os países da OCDE e a quinta da Zona Euro. A população NEET representava quase 17\% dos jovens entre os 15 e os 29 anos, sendo que, em menos de uma década, o número de jovens NEET aumentou quase 4\% (OCDE, 2014). Em 2005 os jovens NEET representavam 12,9\% dos jovens entre os 15-29 anos, número que alcançou em 2012, 16,6\% dos jovens neste escalão etário, estando 11,8\% em situação de desemprego e os restantes inativos.

Dados mais recentes (OCDE, 2018) indicam que, nos países da OCDE, em média, cerca de metade $(52,9 \%)$ dos jovens entre os 18 e os 24 anos $^{12}$ estudam, um terço $(32,7 \%)$ não estuda mas está a trabalhar, e 14,5\% são NEET. No grupo etário em análise, em Portugal, dos jovens com idades compreendidas entre os 18-24 anos, 54,4\% encontravam-se inseridos no sistema educativo, 30,4\% apesar de estarem fora da educação, mantinham-se integrados no mercado de

\footnotetext{
${ }^{12}$ Neste relatório, a análise centra-se nos indivíduos com idades compreendidas entre os 18 e os 24 anos, na medida em que, neste escalão, a escolaridade obrigatória não afeta a proporção de inativos ou desempregados, quando uma percentagem considerável de jovens continua os estudos após a escolaridade obrigatória. Esta faixa etária 1824 anos é, portanto, uma boa referência para captar a transição de jovens adultos da educação para o trabalho (OCDE, 2017a)
} 
trabalho e 15,2\% eram NEET (6\% de inativos e 9.2\% de desempregados). Ao observar a atual conjuntura do nosso país, no que se refere ao grupo etário mais alargado (15-29 anos), deparamo-nos com uma taxa NEET de 12,4\%, sendo que a divisão deste grupo por escalões mais circunscritos, manifesta claras diferenças: entre os 15-19 anos regista-se uma taxa de $4,3 \%$, aumentando para $17,1 \%$ no período etário dos $20-24$ anos e descendo para $16 \%$ na faixa etária dos 25-29 anos (OCDE, 2018). De salientar, ainda, as dissemelhanças (15-29 anos) da taxa NEET entre os jovens inativos $(5,1 \%)$ e os jovens desempregados $(7,4 \%)$.

Dando conta de alguns indicadores portugueses, respeitantes a 2016 (INSTITUTO NACIONAL DE ESTATÍSTICA, INQUÉRITO AO EMPREGO), constata-se que a taxa de desemprego jovem tem vindo a decrescer a um ritmo superior à do desemprego total do país, tornando-se essa variação mais expressiva no grupo do sexo feminino. Numa comparação entre os anos 2013 e 2016, enquanto a população total registava uma taxa de desemprego de 16,1\% e $11 \%$, respetivamente, a taxa de desemprego da população jovem (15-29 anos) passou de 28,5\% (2013) para 20,6\% (2016). Seguindo a tendência do desemprego jovem, a taxa NEET sofreu, similarmente, uma redução entre o período 2013-2016, atingindo os 12,3\% em 2016 (o que representa uma redução de 0,4\% face ao ano anterior e 3,6\% face a 2013). Sublinha-se que o decréscimo registado assume maior significância no escalão etário 25-29 anos, em que a diminuição face a 2013 é de 3,7\% (apesar de se ter registado um ligeiro crescimento relativamente a 2015), enquanto o grupo mais jovem (15-24 anos) registou uma redução de $3,4 \%$.

Quanto ao abandono escolar precoce, assumido como um importante indicador de análise do universo NEET, é de salientar o esforço feito por Portugal, embora em 2016 se tenha observado uma ligeira inflexão na tendência decrescente registada na última década e que, em parte, será justificada pelo aumento das taxas de retenção escolar, potenciadoras de situações de abandono no curto e médio prazo (GARANTIA JOVEM, 2016). Seguramente, o combate do abandono escolar precoce revela-se fundamental para enfrentar o desafio NEET, logo, os governos deverão garantir que todos os jovens concluam, pelo menos, o ensino secundário, no sentido do prosseguimento dos seus estudos ou do desenvolvimento de competências profissionais essenciais a uma integração bem-sucedida no mercado de emprego, paralelamente a uma deteção precoce de situações de risco e posterior intervenção (OCDE, 2016). Ainda que os países da OCDE tenham vindo a registar uma evolução positiva ao longo da última década, no que diz respeito à redução das taxas de abandono escolar precoce, a verdade é que um em cada seis jovens (25-34 anos) não possui qualificações de nível secundário, sendo a taxa 
substancialmente mais elevada nos países do sul da Europa, onde Portugal se insere (OCDE, 2016).

O Inquérito ao Emprego avançado pelo Instituto Nacional de Estatística (INE), referente ao $2^{\circ}$ Trimestre de 2018 , permite-nos analisar dados mais recentes, constatando-se que, do total de 2 215,9 mil jovens (dos 15 aos 34 anos), 8,9\% (197,2 mil) não estavam a trabalhar, nem inseridos no sistema educativo/formativo. Neste período, este amplo grupo etário era constituído, sobretudo, por mulheres (52,8\%), indivíduos dos 25 aos 34 anos (57,8\%), com um nível de escolaridade correspondente, no máximo, ao $3 .^{\circ}$ ciclo do ensino básico $(45,7 \%)$ e desempregados $(52,1 \%)$. Face ao trimestre anterior, a taxa de jovens NEET registou uma diminuição de 1,6 pontos percentuais. No que se refere ao $2^{\circ}$ trimestre de 2017 , a percentagem de jovens NEET entre os 15-34 anos obteve uma diminuição de 1,9 pontos percentuais $(44,7$ mil), a qual resulta, essencialmente, da diminuição do número de jovens NEET do sexo feminino (2,2 p.p.), sendo maior no grupo etário dos 25 aos 34 anos (3,0 p.p.), bem como para aqueles com um nível de escolaridade completo correspondente, no máximo, ao $3 .^{\circ}$ ciclo do ensino básico (2,2 p.p.). Não obstante o conjunto de indicadores, brevemente apresentado, seja demonstrativo de uma evolução otimista, o número de jovens NEET em Portugal requer atenção constante, concretizada através de ações que potenciem o desenvolvimento holístico dos jovens e uma integração de qualidade no mundo do trabalho.

Importa, ainda, destacar algumas conclusões indicativas da relação entre a experiência NEET, em idade mais avançada, e os níveis de competência avaliados pelo Programme for International Student Assessment (PISA) ${ }^{13}$. Conscientes do impacto negativo das baixas qualificações na economia e no acesso dos cidadãos ao mercado de trabalho, os resultados do PISA mostram que, de facto, em muitos países, uma grande parte dos alunos não conseguiu alcançar o nível 2 numa escala de 6 níveis, antevendo uma falha grave, mediante as competências básicas, essenciais para ler e compreender textos simples, ou para dominar conceitos e procedimentos matemáticos e científicos básicos. Neste contexto, e mesmo que os dados provenientes da avaliação PISA sejam, apenas um entre outros indicadores que devemos considerar para equacionar estas problemáticas, os dados disponíveis sugerem a existência de uma relação entre a proporção de alunos com 15 anos de baixa qualificação e com baixo desempenho e a percentagem de NEET entre os 15-19 anos de idade (OCDE, 2017a).

\footnotetext{
${ }^{13}$ Estudo internacional desenvolvido pela OCDE, cujo principal objetivo assenta na avaliação da capacidade que os alunos de 15 anos, de diferentes países, apresentam para mobilizar os seus conhecimentos nos domínios da Matemática, da Leitura e das Ciências e enfrentar desafios que a transição para a vida adulta lhes coloca (FERREIRA, FLORES \& CASAS-NOVAS, 2017).
} 
Por último, considerando o recente relatório alusivo à economia portuguesa (OCDE, 2017b), que alerta para a existência de baixos salários e fortes indicadores de trabalho precário dos jovens portugueses e, tendo em linha de conta, um dos objetivos da Agenda 2030 para o desenvolvimento sustentável - promover o crescimento económico inclusivo e sustentável, o emprego pleno e produtivo e o trabalho digno para todos - urge não só combater o abandono escolar precoce e reduzir, substancialmente, a proporção de jovens sem emprego, educação ou formação, mas também, aumentar o nível de qualificações da população, em geral (MINISTÉRIO DOS NEGÓCIOS ESTRANGEIROS, 2017). É, ainda, essencial garantir o cumprimento de duas importantes conquistas civilizacionais trazidas pela modernidade: "o direito à educação ao longo da vida e o direito a formas de trabalho mais dignas e humanizadas" (ALCOFORADO, 2014, p.14).

\section{Iniciativas políticas para a qualificação e emprego dos jovens}

A elevada taxa de desemprego juvenil e a percepção inequívoca das graves consequências desta circunstância, nas esferas económica e social, estiveram na génese de um conjunto de iniciativas políticas levadas a cabo pela Comissão Europeia, constituindo a promoção da empregabilidade dos jovens a grande prioridade. Deste modo, foram fixadas metas e objetivos específicos nos setores da educação, qualificação, emprego e inovação, como ponto de partida para a operacionalização e consolidação de medidas interventivas essenciais à edificação de um futuro tão almejado, conduzindo a distintas ações políticas distribuídas por três categorias principais, nomeadamente, medidas educativas, medidas relativas ao emprego e medidas facilitadoras da transição entre a escola e o mercado de trabalho.

Estabelecido o contributo de níveis de qualificação mais elevados para o crescimento de um país, a educação assume-se como uma componente preponderante quando se fala em políticas dirigidas à empregabilidade dos jovens. A este respeito, Alcoforado (2008, p.119) afirma que "sendo a qualificação o principal elemento organizador e minimamente regulador do mercado de trabalho, a educação e a formação terão de se organizar para responder à procura individual e social de obtenção de qualificações e de garantia de mobilidade". As medidas educativas traçadas neste âmbito incluem tanto a prevenção do significativo abandono escolar precoce, como a reintegração dos jovens, fruto desse abandono, no sistema educativo e/ou formativo. A redução da percentagem de jovens que abandonam a escola precocemente (para uma percentagem inferior a 10\%), ao constituir um dos principais desígnios da UE, traduz um 
alargado consenso em torno da necessidade de aumentar o tempo de permanência e envolvimento na escola (STONE III, 2014). Com base neste pressuposto, muitos países avançaram com a implementação de um conjunto de medidas, destacando-se os percursos curriculares alternativos, planos de assistência escolar e novos programas de formação profissional, assentes na dupla certificação, conciliada com a formação prática em contexto de trabalho (EUROFOUND, 2011).

Note-se que, iniciativas deste cariz, há muito se inscrevem na miríade de preocupações alusivas às transições escola-trabalho dos jovens. Basta recordar Bertrand Schwartz, uma das personalidades incontornáveis do movimento da Educação Permanente que, a par do desenvolvimento de inovadoras experiências pedagógicas, implementou o prestigiado "Nouvelles Qualifications", um programa destinado a jovens com dificuldades de inserção profissional, associadas às baixas qualificações (ALCOFORADO, 2008).

No que diz respeito às políticas de emprego, temos vindo a assistir ao incremento de uma série de incentivos, baseados na atribuição de apoios financeiros, para incitar o tecido empresarial a recrutar, formar e criar postos de trabalho para os jovens (e adultos), proliferando, ainda, programas impulsionadores da criação do próprio emprego. O período crítico que marca a transição para a vida adulta, mediante os novos contornos, tem vindo a ser acompanhado de diversas iniciativas políticas, facilitadoras de trajetórias bem-sucedidas entre o sistema educativo e o mercado de trabalho, prosseguindo uma abordagem concertada, na qual se inserem programas de informação, aconselhamento e orientação vocacional, apoio na procura ativa de emprego e acesso a estágios. Em 2012, num contexto de crise internacional, em que um elevado número de jovens não se encontrava a trabalhar nem a estudar, através da Recomendação do Conselho - 2013/C 120/01 - de 22 de abril de 2013, o Conselho da União Europeia recomendou aos Estados-Membros o estabelecimento de uma Garantia para a Juventude.

Portugal deu cumprimento à referida Recomendação, através da aprovação da Resolução do Conselho de Ministros n. ${ }^{\circ}$ 104/2013, de 31 de dezembro de 2013 que inclui o "Plano Nacional de Implementação de uma Garantia Jovem", enquadrando tal iniciativa numa metodologia de intervenção que visa assegurar, no espaço de quatro meses, uma resposta (trabalho ou continuidade do processo de aprendizagem com vista à melhoria das qualificações) aos jovens até aos 29 anos que não estão a trabalhar, não estão a estudar, nem estão a frequentar formação (RESOLUÇÃO DO CONSELHO DE MINISTROS nº105/2013). Nesta iniciativa, 
pretende-se envolver os jovens desempregados e os jovens inativos ou desencorajados ${ }^{14}$. Naturalmente, este último grupo representa o foco de maior preocupação, pois o facto de não se encontrarem registados no Serviço Público de Emprego, compromete, seriamente, a sua sinalização.

Numa referência às ações desenvolvidas em Portugal, no âmbito da Garantia Jovem (GARANTIA JOVEM - RELATÓRIO ANUAL 2016), assinalam-se dois níveis de intervenção distintos: Intervenção Precoce e Ativação (sinalização, diagnóstico, acompanhamento e encaminhamento dos jovens para a medidas de apoio à integração no mercado de trabalho) e Medidas de Resposta/Integração no Mercado de Trabalho (educação e formação, estágios e emprego). No que toca ao direcionamento de políticas públicas a grupos com maiores défices, ao nível da promoção da empregabilidade, é importante ter presente os efeitos, de certa forma limitados, associados a estes investimentos, sobressaindo, por parte dos estados, o fraco interesse em compreender que, no sucesso e acesso ao mercado de emprego, a formação conjetura um requisito necessário, mas jamais será suficiente. Efetivamente, a condição social dos agentes envolvidos, os jogos de interesses e de poder em que eles se encontram e as dinâmicas que caracterizam as economias serão, perpetuamente, fortes determinantes em todos estes processos (ALCOFORADO; FERREIRA, 2011).

Ainda que reconhecido o impacto considerável das decisões de política nacional nas oportunidades proporcionadas aos jovens em termos de qualificação e emprego, muito poderá ser feito a nível das políticas locais, pelo que a coordenação e a coerência entre os papéis e ações das autoridades existentes deverão constituir uma das valências a otimizar. Nesta linha de ideias, uma ação precoce poderá potencializar, em larga medida, o papel das autarquias locais e das instituições educativas, já que a estas deverá ser atribuída a incumbência e o compromisso de trabalharem em prol da equidade de todas as crianças, jovens e famílias (PUBLIC HEALTH ENGLAND, 2014). Embora comprovada a eficácia da implementação de um conjunto de medidas preventivas, torna-se irrealizável impedir que alguns jovens atravessem circunstâncias de afastamento da educação e do mercado de trabalho, daí que as próprias autarquias locais devam assegurar e responsabilizar-se pela disponibilização de

\footnotetext{
${ }^{14}$ Identificada a dificuldade em sinalizar os jovens inativos, cujo peso no universo NEET tem sido crescente, Portugal teve o apoio da OIT para desenvolver um trabalho de caracterização deste público e definir uma estratégia integrada de sinalização e apoio aos jovens NEET não registados no Serviço Público de Emprego. A implementação desta estratégia constituiu um dos objetivos para o ano 2017, que se prolongará até 2020 (Garantia Jovem - Relatório Anual 2016).
} 
programas específicos reservados àqueles que se tornaram NEET, no sentido de promover melhores condições de vida.

Perante o grande desígnio da diminuição do número de jovens NEET, o trabalho concertado com o tecido empresarial local, que privilegia a comunicação entre empregadores, autoridades locais e escolas, assume particular importância, sobretudo, quando se fala de planeamento da oferta educativa e formativa, de modo a que sejam consideradas e conciliadas, em todo este processo, as necessidades das empresas e os interesses e aspirações dos próprios jovens, visando o aumento das oportunidades de emprego após a conclusão de um percurso educativo ou formativo (PUBLIC HEALTH ENGLAND, 2014).

Tendo por base exemplos de boas práticas, neste trabalho limitamo-nos a mencionar alguns princípios comuns que poderão ser considerados no desenho de políticas e projetos de intervenção com jovens NEET (ou em risco de se tornarem). Em primeiro lugar, é imprescindível garantir que as ofertas formativas apresentadas sejam, de facto, apropriadas e projetadas de forma a atrair os jovens que estão alienados, potenciando, ao mesmo tempo, o desenvolvimento de competências essenciais à sua integração no sistema educativo/formativo ou no mercado de trabalho. De salientar que embora um número expressivo de jovens tenda a manifestar, de um modo geral, maior interesse por competências mais relacionadas com o trabalho (técnicas), jamais poderá ser menorizada uma formação mais transversal, nomeadamente de natureza sociocultural, a qual, para além de igualmente valorizada nos processos de transição (OFSTED, 2010), garantirá, a médio prazo, uma menor probabilidade de desfasamento entre os processos de desenvolvimento pessoal e as idiossincrasias do trabalho e do emprego.

Outro ponto de interesse prende-se com o acesso a uma certificação, dado constituir um recurso atrativo para os jovens, promotor da sua autoconfiança e empregabilidade e, consequentemente, da redução dos níveis NEET (OFSTED, 2010). O facto de os jovens NEET se sentirem menos atraídos pelo sistema escolar, devido às situações negativas anteriormente experienciadas, dificulta em grande medida a sua reintegração, sendo esta mais provável se a oferta disponibilizada não for semelhante àquela que era proporcionada (DAVIES, 2005; PAYNE, 2002 cit in SACHDEV; HARRIES; ROBERTS, 2006). Assim, a aposta em ambientes educativos não formais (associações juvenis/centros sociais), conjugada com programas flexíveis e adaptáveis, em função das necessidades e interesses dos participantes, poderão concorrer para bons níveis de comprometimento e retorno à atividade educativa (DEPARTMENT FOR CHILDREN SCHOOLS AND FAMILIES, 2008). Os incentivos 
financeiros, garantindo um rendimento estável e permitindo uma gestão mais autónoma da vida, afiguram-se, igualmente, como um importante estímulo para os jovens permanecerem nos programas educativos/formativos, dado impulsionarem a superação de alguns dos obstáculos à participação e aumentarem as taxas de vinculação (MAGUIRE, 2013).

Apresentadas algumas recomendações de intervenção junto do público NEET, baseadas na sinalização de boas práticas, gostaríamos de finalizar esta secção com algumas considerações relativas às perceções dos próprios jovens, face ao seu envolvimento em iniciativas desta índole, pois acreditamos que dar-lhes voz será, certamente, um passo importante neste longo caminho de descoberta e consolidação das melhores respostas à problemática. É, sem dúvida, indispensável explorar e compreender as reais necessidades dos jovens quanto ao processo de transição para a vida adulta, em especial, na fase de procura de emprego. Neste sentido, a título de exemplo, destaca-se o trabalho desenvolvido por Seddon, Hazenberg \& Denny (2013), cujos resultados apontam para grandes benefícios de programas e iniciativas desenvolvidas neste âmbito, nos quais se incluem: a influência ambiental positiva, associada a uma rotina diária e novas atividades, bem-estar psicológico, maior recetividade a novos desafios e sentimento de inclusão social; e o aumento do capital pessoal, determinado pelo desenvolvimento de competências sociais, autoconfiança, motivação e uma clara mudança de atitude em relação ao futuro, traduzida na capacidade de traçar planos mais focados e realistas para as suas carreiras.

\section{Considerações finais}

O cenário europeu, ao qual Portugal não é alheio, tem vindo a manifestar uma complexidade imensa no que às elevadas taxas de desemprego diz respeito, atingindo, especialmente, o segmento mais jovem da população. Esta ocorrência transformou-se num grave problema de política social, na maioria das sociedades industrializadas, nos últimos anos, caracterizado por profundas divergências entre as qualificações, competências e experiências dos jovens e as exigências de um mercado de trabalho cada vez mais volátil e global, daí que as taxas de desemprego juvenil sejam, consistentemente, mais expressivas do que as da população adulta (NOH; JOO LEE, 2017).

Mesmo que estejamos perante a geração mais qualificada de sempre, assiste-se a uma dificuldade acrescida "no acesso ao mercado de trabalho, o qual se encontra saturado e mal regulado. A regulação, quando existente, tem lacunas e subterfúgios que propiciam situações de exploração e trabalho precário, lançando a instabilidade no espaço pessoal dos jovens e no 
próprio tecido económico da sociedade em que se inserem" (RODRIGUES, 2016, p. 67). Neste contexto, o mercado de emprego não poderá continuar a ser classificado em termos de uma simples dicotomia de emprego e desemprego, pois a zona de precariedade constitui, atualmente, uma realidade alarmante, exigindo um novo olhar, uma nova interpretação e, consequentemente, iniciativas mais abrangentes, direcionadas e ajustadas à multiplicidade de conjunturas. Salienta-se, assim, a título de exemplo, a necessidade de as políticas alargarem o seu leque de medidas, a fim de facilitar a integração dos jovens no mercado de trabalho, independentemente das suas qualificações.

A categoria NEET, amplamente utilizada para definir e capturar níveis de vulnerabilidade e desvinculação de uma franja cada vez mais diversificada de jovens, vem reconhecer os riscos inerentes às transições prolongadas da juventude para a idade adulta, totalmente fragmentadas por perspetivas incertas. Com efeito, o afastamento da educação, da formação e do emprego inviabiliza a acumulação de capital humano através de canais formais, conduzindo a geração jovem a situações de exclusão social e pobreza.

Tendo em consideração a multiplicidade e a complexidade das questões envolvidas na identificação e compreensão das causas, especificidades e impacto psicossocial da situação NEET, torna-se essencial que, tanto o domínio da investigação científica, como o setor das políticas se envolvam numa reflexão conjunta que permita a desagregação dos distintos subgrupos, pois, tal como ficou demonstrado ao longo deste trabalho, a heterogeneidade de características, fatores de risco, consequências e necessidades são imensuráveis (FURLONG, 2006). Este diálogo reflexivo deverá alicerçar-se, manifestamente, numa abordagem holística (das ciências sociais), pois há papéis importantíssimos a serem desempenhados por profissionais de distintas áreas do saber.

Revela-se, então, profícuo o comprometimento da União Europeia na definição de políticas eficazes que visem a imprescindível reforma do mercado de trabalho e, ao mesmo tempo, que propiciem e capacitem os jovens a planear e a implementar projetos de vida realistas e desafiantes, dos quais fazem parte a obtenção de um emprego estável, com um rendimento adequado às qualificações e competências pessoais e profissionais. Daqui ressalta, no contexto do movimento da Educação e Formação ao Longo da Vida, a necessidade de qualquer indivíduo se poder situar face ao conhecimento, aos seus percursos, experiências e oportunidades, seguindo os caminhos que melhor se adaptem às suas particularidades, às especificidades dos contextos e aos seus projetos de vida (ALCOFORADO, 2008). 
Assim, as políticas públicas e os programas financiados pela União Europeia, têm procurado orientar-se para uma melhoria gradual da qualidade da oferta educativa e para o favorecimento de processos de decisão mais informados e acompanhados, entendendo esta confluência como a melhor opção para potenciar o encontro entre os interesses dos jovens e as dinâmicas da economia e das empresas, diversificando as vias formativas e configurando ofertas integradas, muitas vezes em alternância, passíveis de ajudar a mitigar e a prevenir os riscos e vulnerabilidades sociais. De igual forma, é essencial travar a interpretação generalizada, sobretudo, a nível das atuais políticas, ancorada na responsabilização das atitudes dos próprios jovens, quando esta circunstância tem sido, manifestamente, repercussão de um conjunto de fatores associados à instabilidade laboral e ao aumento das taxas de desemprego.

Ao longo das últimas décadas, o caminho trilhado por Portugal em termos da qualificação da sua população, alicerçado na tentativa de recuperar o atraso face a outros países da UE e da OCDE é, sem dúvida, inegável. Todavia, este atraso é, ainda, notório, persistindo baixos níveis de qualificação. Tal cenário, associado ao preocupante abandono escolar precoce, vem complexificar, em larga escala, a ligação à formação e ao desenvolvimento de novos conhecimentos, dificultando ou até mesmo impossibilitando, não só a criação de uma base sólida de competências, mas também, o envolvimento dos indivíduos em contextos de mobilidade profissional e de reestruturação económica.

Considerando a atual extensão do desemprego juvenil e o impacto desta conjuntura, e de outros problemas associados, a nível pessoal, social e económico, torna-se imperativo conhecer e compreender as idiossincrasias do fenómeno, viabilizando uma intervenção de qualidade, sustentada por um acompanhamento rigoroso e adequado, que inclua diretrizes e estratégias altamente diversificadas que respondam à heterogeneidade do grupo NEET.

Inequivocamente, é preciso conhecer para agir, logo, atendendo à escassez de produção científica nesta área, particularmente em Portugal, a aposta em trabalhos de investigação que privilegiem não só o envolvimento dos próprios jovens, mas também a articulação com outros atores e parceiros locais, com responsabilidades neste domínio, reveste-se de grande importância, no sentido de potenciar a reflexão e o incremento de políticas públicas orientadas para a sua natureza multidimensional, numa lógica de promoção da qualificação e empregabilidade dos jovens e de combate a situações geradoras de exclusão social. Com efeito, a aposta em estratégias que potenciem transições bem-sucedidas da escola para o trabalho deverá constituir uma prioridade, independentemente do clima económico e, a concretização desta missão tem de passar, obrigatoriamente, por um trabalho concertado que possibilite o 
desenvolvimento das competências essenciais ao mercado de trabalho e à cidadania ativa, no qual o envolvimento e a mobilização de distintos atores da comunidade se revela determinante.

\section{REFERÊNCIAS}

AGUILA, Ema., MEJÍA, Nelly., PÉREZ, Francisco., RIVERA, Alfonso \& RAMÍREZ, Edgar. Pobreza Y Vulnerabilidad En México: El Caso De Los Jóvenes Que No Estudian Ni Trabajan. Estudios Económicos, v. 30, n. 1, p. 3-49, 2013.

ALCOFORADO, Luís.; FRIAS, Mafalda.; CORDEIRO, António Manuel Rochette; FONSECA, António Castro \& OLIVEIRA, Marta. Educação e (não) Trabalho. Indagações sobre uma relação sempre controversa, a propósito dos jovens que não estudam nem trabalham. Cadernos de Pesquisa: Pensamento Educacional, v. 13, n. 34, p. 38-58, 2018.

ALCOFORADO, Luís. Uma Educação para Todos, ao Longo e em todos os Espaços da Vida: desafios para a construção de políticas públicas promotoras de uma cidadania planetária crítica e ativa. In: SILVA, Marinalva Freire da. Mundos Distantes, Diálogos Possíveis: a vida em Mosaico. João Pessoa: Ideia, 2014. p. 14-34.

ALCOFORADO, Luís \& FERREIRA, Sónia Mairos. Educação e Formação de Adultos. Nótulas sobre a necessidade de descomprometer a Cinderela, depois do beijo do Príncipe Encantado. In: ALCOFORADO, Luís; FERREIRA, Joaquim Armando; FERREIRA, António Gomes; LIMA, Margarida Pedroso de; VIEIRA, Cristina; OLIVEIRA, Albertina \& FERREIRA, Sónia Mairos. Educação e Formação de Adultos: políticas, práticas e investigação. Coimbra: Imprensa da Universidade de Coimbra, 2011. p. 7-20.

ALCOFORADO, Luís. Competências, Cidadania e Profissionalidade. Limites e desafios para a construção de um modelo português de Educação e Formação de Adultos. Dissertação de Doutoramento. Faculdade de Psicologia e de Ciências da Educação da Universidade de Coimbra, 2008.

ALFIERI, Sara.; SIRONI, Emiliano.; MARTA, Elena.; ROSINA, Alessandro \& MARZANA, Daniela. Young Italian NEETs (Not in Employment, Education, or Training) and the Influence of Their Family Background. Europe's Journal of Psychology, v. 11, n. 2, p. 311$322,2015$.

ARCEO, Eva. \& CAMPOS, Raymundo. Quiénes son los NiNis en México? In Los grandes problemas de México, 524. México: Centro de Investigación y Docencia Económicas A. C., 2011.

ARNETT, Jeffrey. Emerging Adulthood. A theory of development from the late teens to the late twenties. American Psychologist, v. 55, n. 5, p. 469-480, 2000.

BÃLAN, Mariana. European and national policies regarding social inclusion of NEET youths. Hyperion International Journal of Econophysics \& New Economy, v. 10, n. 2, p. 136-156, 2017. 
BATINI, Frederico.; CORALLINO, Vanessa.; TOTI, Giulia. \& BARTOLUCCI, Marco. NEET: A Phenomenom Yet to Be Explored. Interchange, v. 47, n. 3, p. 19-37, 2016

BENTLEY, Tom. \& GURUMURTHY, Ravi. Destination unknown: engaging with the problems of marginalised youth. London: Demos, 1999.

BLANCH, Josep Maria. La juventud nini, un agujero negro psicosocial. Revista Psicologia, Organizações e Trabalho, v. 14, n. 4, p. 355-366, 2014.

BYNNER, John. \& PARSONS, Samantha. Social Exclusion and the Transition from School to Work: The Case of Young People Not in Education, Employment, or Training (NEET). Journal of Vocational Behavior, v. 60, n. 2, p. 289-309, 2002.

CARCILLO, Stéphane; FERNANDEZ, Rodrigo; KONIGS, Sebastian \& MINEA, Andreea. NEET Youth in the Aftermath of the Crisis: Challenges and Policies. Paris: OCDE, 2015.

COLE, Matthew. Sociology contra government? The contest for the meaning of unemployment in UK policy debates. Work Employment and Society, v. 22, n. 1, p. 27-43, 2008.

COLES, Bob; HUTTON, Sandra; BRADSHAW, Jonathan; CRAIG, Gary, GODFREY, Christine \& JOHNSON, Julia. Literature review of the cost of being 'not in education, employment or training' at age 16-18. (Research Report). Nottingham: Department for Education and Skills, 2002.

DEPARTMENT FOR CHILDREN SCHOOLS AND FAMILIES. Reducing the proportion of young people not in education, employment or training (NEET). The strategy.

Nottingham: DCSF publications, 2008.

ELDER, Glen.; KIRKPATRICK JOHNSON, Monica. \& CROSNOE, Robert. The emergence and development of life course theory. In: SHANAHAN, Michael; MORTIMER, Jeylan \& KIRKPATRICK JOHNSON, Monica (Eds). Handbook of the Life Course. New York: Springer, 2004. p. 3-19.

EUROFOUND. Exploring the Diversity of NEETs. Luxembourg: Publications Office of the European Union, 2016.

EUROFOUND. NEETs - Young people not in employment, education or training: Characteristics, costs and policy responses in Europe. Luxembourg: Publications Office of the European Union, 2012.

EUROFOUND. Young people and NEET's in Europe: First Findings (resumé). Dublin: Fundação Europeia para a Melhoria das Condições de Vida e de Trabalho, 2011.

EUROPEAN COMMISSION, EACEA, EURYDICE \& CEDEFOP. Tackling Early Leaving from Education and Training in Europe: Strategies, Policies and Measures. Eurydice and Cedefop Report. Luxembourg: Publications Office of the European Union, 2014. 
FERREIRA, Ana Sousa; FLORES, Isabel \& CASAS-NOVAS, Teresa. Introdução ao estudo - Porque melhoraram os resultados PISA em Portugal? Estudo longitudinal e comparado (2000-2015). Lisboa: Fundação Francisco Manuel dos Santos, 2017.

FLISI, Sara; GOGLIO, Valentina; MERONI, Elena Claudia \& VERA-TOSCANO, Esperanza. School-to-work transition of young individuals: what can the ELET and NEET indicators tell us? Luxembourg: Publications Office of the European Union, 2015.

FURLONG, Andy. Not a very NEET solution: representing problematic labour market transitions among early school-leavers. Work Employment and Society, v. 20, n. 3, p. 553569, 2006.

GARANTIA JOVEM. Relatório Anual 2016. Instituto do Emprego e Formação Profissional, IP, 2016.

GAUDET, Stéphanie. Tornar-se adulto: um percurso social e singular. In: CASTRO FONSECA, António (Ed.). Jovens adultos. Coimbra: Edições Almedina, 2015. p. 19-46.

HENDERSON, Joanna L; HAWKE, Lisa D. \& CHAIM, Gloria. Not in employment, education or training: mental health, substance use, and disengagement in a multi-sectoral sample of service-seeking Canadian youth. Children and Youth Services Review, v. 75, p. $138-145,2017$.

HOLTE, Bjørn. Counting and Meeting NEET Young People: Methodology, Perspective and Meaning in Research on Marginalized Youth. Young. Nordic Journal of Youth Research, v. 26, n. 1, p. 1-16, 2017.

INSTITUTO NACIONAL DE ESTATÍSTICA. Estatísticas do Emprego 2. ${ }^{\circ}$ trimestre de 2018, 2018.

INTERNATIONAL LABOUR ORGANIZATION. Global Employment Trends for Youth 2017: Paths to a better working future. Geneva: International Labour Office, 2017.

INUI, Akio. Why Freeter and NEET are Misunderstood: Recognizing the New Precarious Conditions of Japanese Youth. Social Work \& Society, v. 3, n. 2, p. 244-251, 2005.

MAGUIRE, Sue. Will raising the participation age in England solve the NEET problem? Research in Post-Compulsory Education, v. 18, n. 1-2, p. 61-76, 2013.

MENDONÇA, Marina; ANDRADE, Cláudia \& FONTAINE, Anne Marie. Transição para a Idade Adulta e Adultez Emergente: Adaptação do Questionário de Marcadores da Adultez junto de Jovens Portugueses. Psychologica, n. 51, p. 147-168, 2009.

MINISTÉRIO DOS NEGÓCIOS ESTRANGEIROS. Relatório nacional sobre a implementação da Agenda 2030 para o Desenvolvimento Sustentável. Portugal: Apresentação Nacional Voluntária no Fórum Político de Alto Nível das Nações Unidas, 2017 
MIRANDA, Ana. Sobre la escasa pertinencia de la categoría NI NI: una contribución al debate plural sobre la situación de la juventud en la Argentina contemporânea. Revista Latinoamericana de Políticas y Administración de la Educación, v. 2, n. 3, p. 60-73, 2015.

NOH, Hyejin \& JOO LEE, Bong. Risk factors of NEET (Not in Employment, Education or Training) in South Korea: an empirical study using panel data. Asia Pacific Journal of Social Work and Development, v. 27, n. 1, p. 28-38, 2017.

O'HIGGINS, Niall. This time it's different? Youth labor markets during the 'great recession'. Comparative Economic Studies, v. 54, n. 2, p. 395-412, 2012.

O’DEA, Bridianne; GLOZIER, Nicholas; PURCELL, Rosemary; MCGORRY, Patrick; SCOTT, Jan; FEILDS, Kristy-Lee; HERMENS, Daniel; BUCHANAN, John, SCOTT, Elizabeth; YUNG, Alison; KILLACKY, Eoin; GUASTELLA, Adam \& HICKIE, Ian. A cross-sectional exploration of the clinical characteristics of disengaged (NEET) young people in primary mental healthcare. BMJ Open, v. 4, n.12. p. 1-8, 2014.

OOMEN, Annemarie \& PLANT, Peter. Early School Leaving and Lifelong Guidance. Jyväskylä: Finnish Institute for Educational Research, 2014.

OCDE. Education at a Glance 2018: OECD Indicators. Paris: OECD Publishing, 2018.

OCDE. Education at a Glance 2017: OECD Indicators. Paris: OCDE Publishing, 2017a.

OCDE. Estudos Económicos da OCDE, Portugal 2017. Aumentar o crescimento e o bemestar. Lisboa: OCDE, 2017 b.

OCDE. Society at a Glance 2016: OECD Social Indicators. Paris: OECD Publishing, 2016.

OCDE. Society at a Glance 2014: OCDE Social Indicators. Paris: OCDE Publishing, 2014.

OFSTED - Office for Standards in Education, Children's Services and Skills. Reducing the numbers of young people not in education, employment or training: what works and why. Manchester: Ofsted, 2010.

PUBLIC HEALTH ENGLAND. Local action on health inequalities: Reducing the number of young people not in employment, education or training (NEET). London: UCL Institute of Health Equity, 2014.

Recomendação do Conselho - 2013/C 120/01 - de 22 de abril de 2013. Jornal Oficial da União Europeia, 2013. Disponível em: < https://eur-lex.europa.eu/legalcontent/PT/TXT/PDF/?uri=CELEX:32013H0426(01)\&from=EN

REIKO, Kosugi. Youth Employment in Japan's Economic Recovery: 'Freeters' and 'NEETs'. The Asia-Pacific Journal, v. 4, n. 5, p. 1-5, 2006.

RENNISON, Joanne., MAGUIRE, Sue., MIDDLETON, Sue. \& ASHWORTH, Karl. Young people not in Education, Employment or Training: evidence from the Education 
Maintenance Allowance Pilots Database. Department for Education and Skills research report, 628. Loughborough: Loughborough University, 2005.

Resolução do Conselho de Ministros N. ${ }^{\circ}$ 104/2013, de 31 de dezembro de 2013. Diário da República n. ${ }^{\circ}$ 253/2013, Série I de 2013-12-31. Disponível em: < https://dre.pt/pesquisa//search/483892/details/maximized

ROBERTS, Steven. Beyond 'NEET'and 'tidy'pathways: considering the 'missing middle'of youth transition studies. Journal of Youth Studies, v. 14, n. 1, p. 21-39, 2011.

RODRIGUES, Carlos. A Contratação Pública Socialmente Responsável ao serviço dos jovens NEET. Análise Europeia - Revista da Associação Portuguesa de Estudos Europeus, v. 1, n. 1, p. 60-90, 2016.

SACHDEV, Darshan; HARRIES, Bethan \& ROBERTS, Thomas. Regional and subregional variation in NEETs - reasons, remedies and impact. UK: Learning and Skills Development Agency, 2006.

SCHOON, Ingrid. Parental worklessness and the experience of NEET among their offspring. Evidence from the Longitudinal Study of young people in England (LSYPE). Longitudinal and Life Course Studies, v. 5, n. 2, p. 129 - 150, 2014.

SEDDON, Fred; HAZENBERG, Richard \& DENNY, Simon. Effects of an employment enhancement programme on participant NEETs. Journal of Youth Studies, v. 16, n. 4, p. 503-520, 2013.

SERGI, Vittorio; CEFALO, Ruggero \& KAZEPOV, Yuri. Young people's disadvantages on the labour market in Italy: reframing the NEET category. Journal of Modern Italian Studies, v. 23, n. 1, p. 41-60, 2018.

SERRACANT, Pau. A Brute Indicator for a NEET Case: Genesis and Evolution of a Problematic Concept and Results from an Alternative Indicator. Social Indicators Research, v. 117, n. 2, p. 401-419, 2014.

SEU - Social Exclusion Unit. Bridging the gap: New Opportunities for 16-18 Year olds not in education, employment or training. London: The Stationery Office, 1999.

SIMMONS, Robin \& SMYTH, John. Crisis of youth or youth in crisis? Education, employment and legitimation crisis. International Journal of Lifelong Education, v. 35, n. 2, p. 136-152, 2016.

STONE III, James. Trajetórias para uma vida adulta produtiva, através do ensino profissional: uma abordagem de desenvolvimento de carreira para o século XXI. In: CASTRO FONSECA, António (Ed.). Jovens Adultos. Coimbra: Almedina, 2014. p. 263 - 292.

SUE, Roger. Dinâmica dos tempos sociais e processo educativo. In: CARRÉ, Philippe. \& CASPAR, Pierre (Ed.). Tratado das Ciências e Técnicas da Formação. Lisboa: Instituto Piaget, 1999, 103-120. 
SUSANLI, Bilgen. Understanding the NEET in Turkey. Eurasian Journal of Economics and Finance, v. 4, n. 2, p. 42-57, 2016.

THOMPSON, Ron. Individualisation and social exclusion: The case of young people not in education, employment or training. Oxford Review of Education, v. 37, n. 6, p. 785-802, 2011.

YUJI, Genda. The "NEET" problem in Japan. University of Tokyo: Institute of Social Science, 2005.

ZUCCOTTI, Carolina \& O'REILLY, Jacqueline. Ethnicity, Gender and Household Effects on Becoming NEET: An Intersectional Analysis. Work, Employment and Society, p. 1-23, 2018.

\section{SOBRE OS AUTORES:}

\section{Mafalda Frias}

Doutoranda, FPCEUC; Faculdade de Psicologia e de Ciências da Educação da Universidade de Coimbra - Portugal; Doutoramento em Ciências da Educação - Especialidade em Educação, Desenvolvimento Comunitário e Formação de Adultos; Centro de Estudos Interdisciplinares do Século XX; Bolseira de Investigação da Fundação para a Ciência e a Tecnologia SFRH/BD/131426/2017. E-mail: friasmafalda@gmail.com

(iD) http://orcid.org/0000-0002-7052-0701

\section{Luís Alcoforado}

Doutor, FPCEUC; Faculdade de Psicologia e de Ciências da Educação da Universidade de Coimbra - Portugal; Ciências da Educação; Centro de Estudos Interdisciplinares do Século XX. E-mail: lalcoforado@fpce.uc.pt

iD http://orcid.org/0000-0003-4425-7011

\section{António Rochette Cordeiro}

Doutor, FLUCC; Faculdade de Letras da Universidade de Coimbra - Portugal; Geografia; Centro de Estudos Interdisciplinares do Século XX. E-mail: rochettecordeiro@ fl.uc.pt

(iD http://orcid.org/0000-0002-8648-3204 